\title{
Synthesis of a Polyhedral Oligomeric Silsesquioxane (POSS) containing Phenyl and DOPO (7Ph-T7-DOPO) and its thermal stability
}

\author{
Feng Zheng, a , Sheng $\operatorname{Han}^{1, \mathrm{~b}}$, Jin $\operatorname{Han}^{2, \mathrm{c}}$ \\ ${ }^{1}$ School of Shanghai Institute of Technology, Shanghai, 200235, China. \\ ${ }^{2}$ Key Laboratory of Marine Materials and Related Technologies, Zhejiang, Key Laboratory of Marine \\ Materials and Protective Technologies, Ningbo Institute of Materials Technology and Engineering, \\ Chinese Academy of Sciences, Ningbo 315201, Zhejiang \\ a751683686@qq.com, ${ }^{b}$ hansheng654321@sina.com, ${ }^{\mathrm{c}}$ hj@nimte.ac.cn
}

Keywords: polyhedral oligomeric silsesquioxanes, DOPO, 7Ph-T7-Vinyl, 7Ph-T7-DOPO, flame retardant

\begin{abstract}
A new type of polyhedral oligomeric silsesquioxane (POSS) (7Ph-T7-Vinyl) containing phenyl and 9, 10-dihydro-9-oxa-10-phosphaphenanthrene-10-oxide (DOPO) was synthesized from phenyltrimethoxysilane, trichlorovinylsilane, and DOPO in high yield. This product was subjected to addition reaction using an AIBN catalyst in toluene. The structure of 7Ph-T7-DOPO was characterized by 1HNMR and FTIR, and 7Ph-T7-DOPO exhibited a crystal structure of (RSiO1.5) n. TGA curve analysis showed the high thermal stability of the cage-like compound. The flame-retardant properties of the EP composites were also tested in terms of limiting oxygen index (LOI) and UL-94. Incorporation of 2.5 wt. \% DOPO-POSS into epoxy resin (EP-2.5) resulted in an LOI of 27.5 and UL-94 rating of $\mathrm{V}-1(\mathrm{t} 1=34 \mathrm{~s}$ and $\mathrm{t} 2=0 \mathrm{~s})$. All of these results suggested that the 7Ph-T7-DOPO exhibited high thermal stability.
\end{abstract}

\section{Introduction}

Organic-inorganic hybrid composites combine the advantages of inorganic materials and organic polymers. Such composites are generally considered to be a new generation of high-performance materials. Polyhedral oligomeric silsesquioxanes (POSS) are cage-like hybrid molecules consisting of silicon and oxygen $[1,2]$. These compounds can be represented as $\left(\mathrm{RSiO}_{1.5}\right) \mathrm{n}$, where $\mathrm{n}$ is an even number $(n \geq 6)$, $R$ is hydrogen or any alkyl, alkylene, aryl, arylene, or organofunctional derivative of alkyl, alkylene, arylene groups, and Si-O is the inorganic key [3,4]. Considering that the side group R can result in a diverse array of silsesquioxanes [5], organic-inorganic hybrid materials can facilitate development of high-performance materials that combine the desirable properties of conventional organic and inorganic components; such properties include thermal stability, solubility, and processability [6].

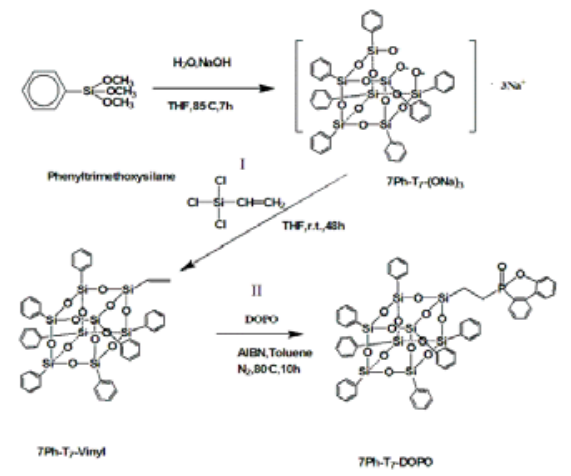

Fig1. Illustration for the synthesis of 7Ph-T7-Vinyl and 7Ph-T7-DOPO

Phosphorus compounds have been investigated in epoxy resins, and findings show that these compounds can impart flame retardancy through flame inhibition in the gas and condensed phases. 
DOPO, a cyclic phosphate with a diphenyl structure, exhibits high thermal stability, oxidation resistance, and good water resistance [7]. DOPO is always incorporated into epoxy resins or other polymers to improve their flame-retardant properties and thermal stability [8]. It is believed that the chemical structure of such materials containing both of phosphorus and DOPO would show excellent flame-retard performance. Thus, our project aims to synthesize a new type of caged phosphorus-containing silsesquioxane by introducing DOPO to silsesquioxane moLecules.

In this study, we prepared DOPO-POSS via hydrolysis of trichlorosilanes [9] and POSS-containing nanocomposites using simple organic reactions (nucleophilic substitution and radical addition) to introduce different phosphorus substituents to the periphery of silsesquioxanes [10]. A new phosphorus-containing POSS (7Ph-T $7-D O P O)$ was synthesized via a three-step pathway (Scheme 1), and the structure of the product was characterized by ${ }^{1}$ HNMR and FTIR. Thermogravimetric analysis (TGA) and DTG were performed to systematically evaluate the chemical and physical properties of $7 \mathrm{Ph}-\mathrm{T}_{7}-\mathrm{DOPO}$, and its EP composites were tested in terms of limiting oxygen index (LOI) and UL-94.

\section{Experimental}

\subsection{Sample preparation}

Synthesis of $7 \mathrm{Ph}-\mathrm{T}_{7}-(\mathrm{ONa})_{3}$. Phenyltrimethoxysilane $(91.20 \mathrm{~g}, 0.46 \mathrm{moL})$, THF $(500 \mathrm{~mL})$, distilled water (10.5 g, $0.58 \mathrm{moL})$, and sodium hydroxide $(7.9 \mathrm{~g}, 0.2 \mathrm{moL})$ were charged into a three-necked flask equipped with a reflux condenser. The mixture was refluxed at $85^{\circ} \mathrm{C}$ for $7 \mathrm{~h}$ with magnetic stirring. The system was cooled to room temperature and left for another $6 \mathrm{~h}$. THF was then distilled off until a white solid substance was obtained.

Synthesis of $7 P h-T_{7}$-Vinyl. THF $(450 \mathrm{~mL})$ was used to dissolve $7 \mathrm{Ph}-\mathrm{T}_{7}-(\mathrm{ONa})_{3}$, and trichlorovinylsilane $(4 \mathrm{~mL})$ was gradually added dropwise into a three-necked flask by syringe. The mixture was stirred at room temperature for $48 \mathrm{~h}$ to obtain a white powder (10.45 g, yield: $44.95 \%$ ).

Synthesis of $7 \mathrm{Ph}-T_{7}-D O P O$. 7Ph-T 7 -Vinyl (0.88 g, $\left.0.90 \mathrm{mmoL}\right)$, DOPO (0.3687 g, $\left.1.707 \mathrm{mmoL}\right)$, AIBN (0.616 g), and toluene $(3.5 \mathrm{~mL})$ were added to a small flask. The mixture was then purged with nitrogen for $10 \mathrm{~min}$ and magnetically stirred at $80^{\circ} \mathrm{C}$ for $10 \mathrm{~h}$ to obtain a white product $(0.4337 \mathrm{~g}$, yield: $40.36 \%)$.

Preparation of DOPO-POSS/EP composites. To realize pre-reaction between DOPO-POSS and epoxy resin, $7 \mathrm{Ph}-\mathrm{T}_{7}$-DOPO was dispersed in diglycidyl ether of bisphenol A (DGEBA) at $140^{\circ} \mathrm{C}$ for $2 \mathrm{~h}$ before curing. The DOPO-POSS contents in the EP composites were adjusted to $0.5 \mathrm{wt} . \%$. After the system was cooled to $70^{\circ} \mathrm{C}$, the curing agent (m-PDA) was added. The equivalent weight ratio of DGEBA to m-PDA was 25:3. The mixtures were cured at $80^{\circ} \mathrm{C}$ for $2 \mathrm{~h}$ and then post-cured at $150^{\circ} \mathrm{C}$ for $2 \mathrm{~h}$ to obtain the product.

\subsection{Measurements}

${ }^{1}$ H NMR were recorded on a Bruker Avance 400 NMR spectrometer operated in Fourier transform mode. $\mathrm{CDCl}_{3}$ was used as the solvent, and the solution was measured with tetramethylsilane (TMS) as the internal reference.

FT-IR spectra were recorded on a NICOLET 6700 IR spectrometer. Spectra were collected by 32 scans with a spectral resolution of $4 \mathrm{~cm}^{-1}$.

Thermogravimetric/differential thermal analysis was performed at a heating rate of $10^{\circ} \mathrm{C} / \mathrm{min}$ under a nitrogen atmosphere and the temperatures ranging from room temperature to $800^{\circ} \mathrm{C}$.

LOI was obtained based on the GB/T2406-93 standard by measuring the minimum oxygen concentration required to support candle-like combustion of EP. An oxygen index instrument (Rheometric Scientific Ltd.) was used on barrels with dimensions of $100 \mathrm{~mm} \times 6.5 \mathrm{~mm} \times 3 \mathrm{~mm}$.

Vertical burning tests were performed based on the UL-94 standard with samples measuring 125 $\mathrm{mm} \times 12.5 \mathrm{~mm} \times 3.2 \mathrm{~mm}$. In this test, the samples were classified as V-0, V-1, V-2, or unclassified according to behavior (dripping of burning material and burning time). 


\section{Results and discussion}

\subsection{Ph-T7-Vinyl.}

$7 \mathrm{Ph}-\mathrm{T}_{7}$-Vinyl was obtained from a substitution reaction between $7 \mathrm{Ph}-\mathrm{T}_{7}-(\mathrm{ONa})_{3}$ and trichlorovinylsilane [Scheme 1(I)]. FT-IR $\left(\mathrm{KBr}, \mathrm{cm}^{-1}\right)$ : 3000-3080 (phenyl), 1500-1600 $\left(\mathrm{CH}_{2}=\mathrm{CH}_{2}\right)$, 1091 (Si-O), 1091 (Si-O-Si). ${ }^{1} \mathrm{HNMR}\left(\mathrm{CDCl}_{3}, \delta\right.$, ppm, TMS): 5.993-6.168 (3H, Si-CH=CH$)$, 7.145-7.779 (35H, $\mathrm{H}$ in phenyl group).

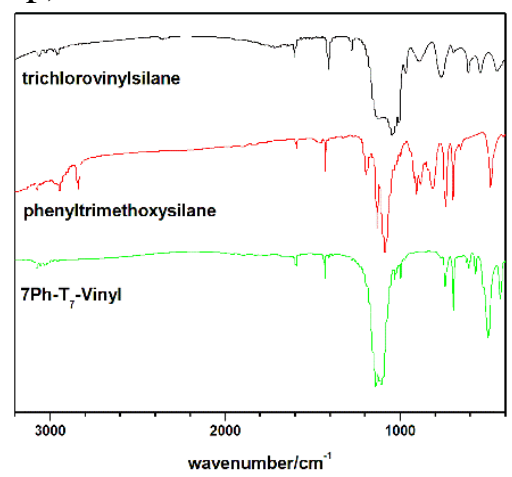

Fig. 1 FT-IR spectra obtained for trichlorovinylsilane, phenyltrimethoxysilane and 7Ph-T7-Vinyl.

The FT-IR spectra of 7Ph-T 7 -Vinyl (Figure 3) indicated the disappearance of the absorbance peak in the region of 2824-2846 $\mathrm{cm}^{-1}$, which is the characteristic of $-\mathrm{OCH}_{3}$. The characteristics of $\mathrm{CH}_{2}=\mathrm{CH}_{2}$ at $1500-1600 \mathrm{~cm}^{-1}$ and phenyl at $3000-3080 \mathrm{~cm}^{-1}$ for $7 \mathrm{Ph}-\mathrm{T}_{7}$-Vinyl were attributed to trichlorovinylsilane and phenyltrimethoxysilane, respectively. Characteristic Si-O-Si absorbance at $1091 \mathrm{~cm}^{-1}$ may also be observed.

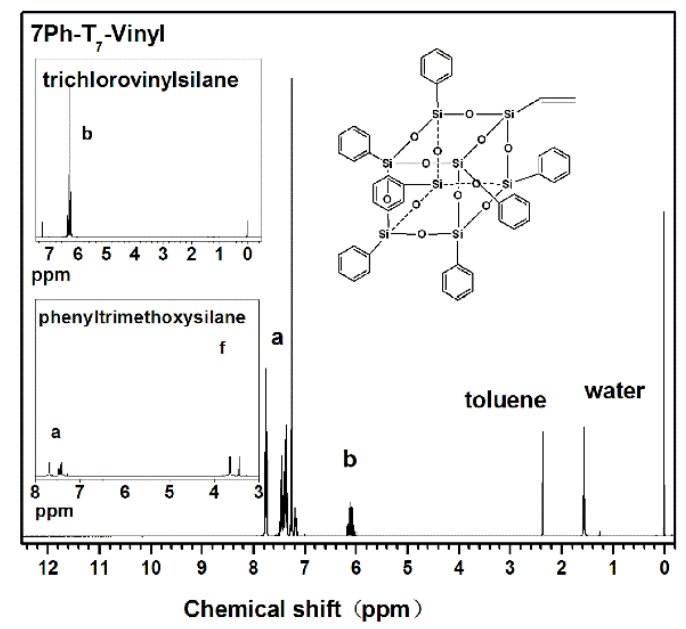

Fig. 2 1H NMR spectra obtained for phenyltrimethoxysilane, trichlorovinylsilane and 7Ph-T7-Vinyl.

The ${ }^{1} \mathrm{H}$ NMR spectrum showed two signals reflecting the chemical structure of $7 \mathrm{Ph}^{-\mathrm{T}_{7}}$-Vinyl (Figure 2). The peaks at 7.14-7.76 ppm (peak a) and 5.99-6.18 ppm (peak b) are ascribed to phenyl and vinyl groups, respectively. The signal of $\mathrm{O}_{-} \mathrm{CH}_{3}$ at 3.652 ppm (peak f) for phenyltrimethoxysilane also completely disappeared in the spectrum of $7 \mathrm{Ph}-\mathrm{T}_{7}-\mathrm{V}$ inyl. The signal at $1.27 \mathrm{ppm}$ may be referenced to toluene, while that observed at $1.5 \mathrm{ppm}$ may be referenced to water.

\subsection{Ph-T7-DOPO.}

7Ph- $\mathrm{T}_{7}$-DOPO was obtained by addition reaction between $7 \mathrm{Ph}^{-} \mathrm{T}_{7}-\mathrm{Vinyl}$ and DOPO [Scheme 1(II)]; FTIR (KBr, $\left.\mathrm{cm}^{-1}\right)$ : 3000-3080 (phenyl and biphenyl), 2890-2940 $\left(\mathrm{CH}_{2}-\mathrm{CH}_{2}\right), 1477$ (P-biphenyl), $1235(\mathrm{P}=\mathrm{O}), 1091$ (Si-O-Si), 914 (P-O-biphenyl). ${ }^{1} \mathrm{HNMR}\left(\mathrm{CDCl}_{3}, \delta\right.$, ppm, TMS): 0.954-1.200 (2H, Si-CH $\left.2_{2}\right)$, 2.186-2.263 (2H, P- $\left.\mathrm{CH}_{2}-\right)$, 7.178-7.940 (43H, $\mathrm{H}$ in phenyl and biphenyl).

In the FTIR spectra of DOPO-Vinyl and 7Ph-T - -DOPO (Figure 3), the characteristic absorbance of $\mathrm{CH}=\mathrm{CH}_{2}$ at $1500-1600 \mathrm{~cm}^{-1}$ completely disappeared compared with that of $7 \mathrm{Ph}-\mathrm{T}_{7}-\mathrm{DOPO}$. New peaks at 1235, 1477, 914, and 3037-3100 $\mathrm{cm}^{-1}$ were attributed to P-O, P-biphenyl, P-O-biphenyl, and biphenyl, respectively. Characteristic $\mathrm{CH}_{2}-\mathrm{CH}_{2}$ absorbance at $2863-2954 \mathrm{~cm}^{-1}$ may also be observed. 


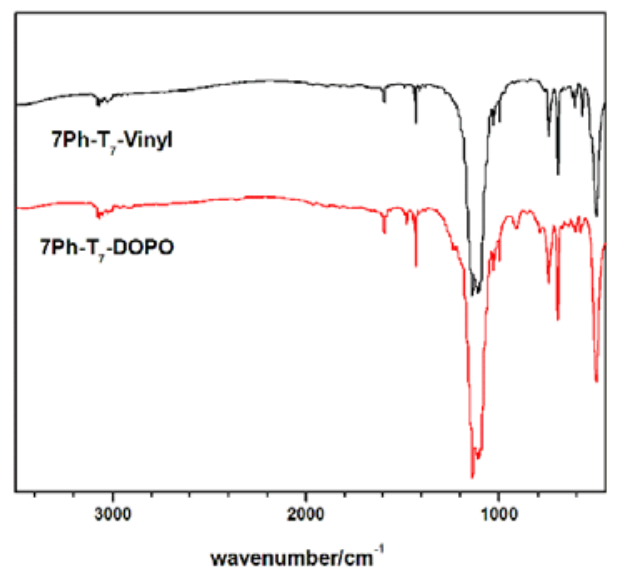

Fig.3 FT-IR spectra of obtained for 7Ph-T7-Vinyl and 7Ph-T7-DOPO.

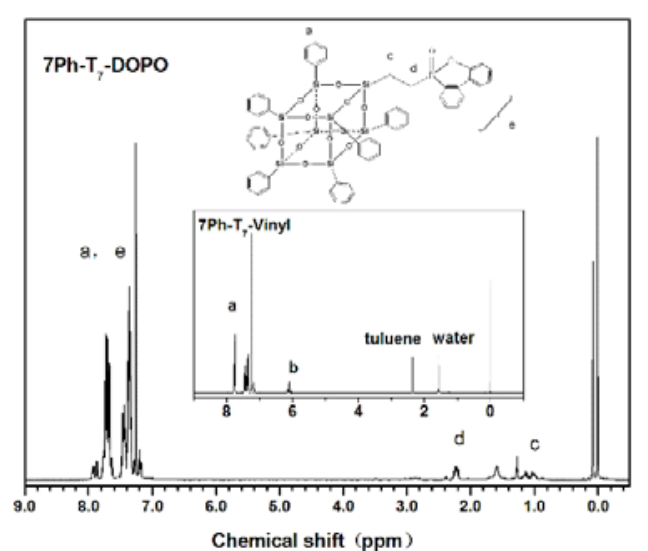

Fig. 4 1H NMR spectra of 7Ph-T7-DOPO

Figure 4 shows the ${ }^{1} \mathrm{HNMR}$ spectra of $7 \mathrm{Ph}-\mathrm{T}_{7}$-Vinyl and $7 \mathrm{Ph}-\mathrm{T}_{7}-\mathrm{DOPO}$. The signal at 5.99-6.18 ppm, which is ascribed to the vinyl groups of $7 \mathrm{Ph}-\mathrm{T}_{7}$-Vinyl, disappeared in the spectrum of 7Ph-T 7 -DOPO. New signals observed at 2.238, 1.011-1.139, and 127.9-137.59 ppm (peaks c, d, and e) in $7 \mathrm{Ph}-\mathrm{T}_{7}-\mathrm{DOPO}$ were also ascribed to methylene protons in $\mathrm{Si}-\mathrm{CH}_{2}, \mathrm{P}-\mathrm{CH}_{2}$, and biphenyl groups, respectively. The signal at $2.34 \mathrm{ppm}$ was referenced to grease, and that observed at $1.5 \mathrm{ppm}$ was referenced to water.

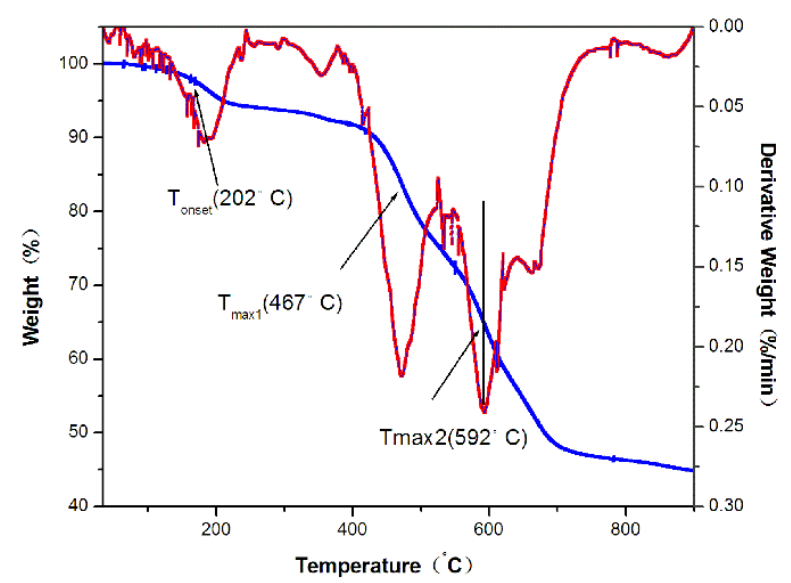

Fig. 5 TGA and DTG curves of 7Ph-T7-DOPO. 


\subsection{Thermogravimetric analysis of 7Ph-T7-DOPO}

The TGA and DTG curves of $7 \mathrm{Ph}-\mathrm{T}_{7}-\mathrm{DOPO}$ are presented in Figure 6. Four decomposition temperatures (Figure 7) were found: Tonset $\left(202^{\circ} \mathrm{C}\right)$, defined as the temperature at which $5 \%$ weight loss occurs; Tmax $1\left(467^{\circ} \mathrm{C}\right)$, defined as the temperature at first maximum weight loss rate; Tmax2 $\left(592^{\circ} \mathrm{C}\right)$, defined as the temperature at second maximum weight loss rate; and char residue at $850^{\circ} \mathrm{C}$. Weight loss in the temperature range of $250-400^{\circ} \mathrm{C}$ was slow and is attributed to residual silanol in DOPO-POSS. The first rapid weight loss between 400 and $550^{\circ} \mathrm{C}$ may be ascribed to degradation of DOPO groups. The second rapid weight loss between 550 and $650^{\circ} \mathrm{C}$ may correspond to phenyl degradation. The remaining residue of $7 \mathrm{Ph}-\mathrm{T}_{7}-\mathrm{DOPO}$ at $850^{\circ} \mathrm{C}$ was $46.2 \%$. Thus, $7 \mathrm{Ph}^{-\mathrm{T}_{7}-\mathrm{DOPO}}$ showed high thermal stability (Figure 6).

\subsection{Flame behavior of the cured EP composites}

LOI values and vertical burning classifications (UL-94) for EP and 7Ph-T 7 -DOPO /EP composites are listed in Table 1.

Incorporation of 2.5 wt. \% $7 \mathrm{Ph}-\mathrm{T}_{7}$-DOPO increased the LOI value of epoxy resin from 24.0 to

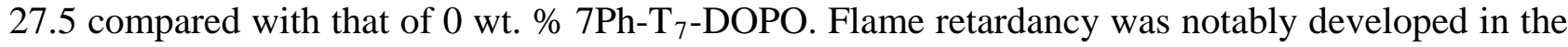
presence of $7 \mathrm{Ph}-\mathrm{T}_{7}-\mathrm{DOPO}$.

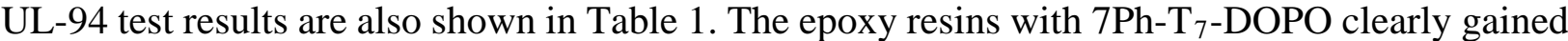
enhanced flame retardancy. Incorporation of $2.5 \% 7 \mathrm{Ph}-\mathrm{T}_{7}-\mathrm{DOPO}$ inhibited dripping and promoted self-extinguishing. The UL-94 rating of resins with $7 \mathrm{Ph}-\mathrm{T}_{7}-\mathrm{DOPO}$ reached $\mathrm{V}-2\left(\mathrm{t}_{1}=34 \mathrm{~s}\right.$ and $\mathrm{t}_{2}=0$ s). All these results indicated that the Polyhedral Oligomeric Silsesquioxane (POSS) containing Phenyl and DOPO (7Ph-T 7 -DOPO) synthesized in this work owned excellent thermal stability.

Table 1 Flame retardancy of DOPO-POSS/EP composites.

\begin{tabular}{|c|c|c|c|c|c|c|c|}
\hline Samples & $\begin{array}{c}\text { Cured } \\
\text { epoxy } \\
\text { Resin(wt.\%) }\end{array}$ & $\begin{array}{c}\text { Content of } \\
7 \mathrm{Ph}_{\text {-T }} \text {-D } \\
\text { OPO } \\
\text { (wt.\%) }\end{array}$ & LOI(\%) & $\begin{array}{c}\text { UL-94 } \\
(3.2 \mathrm{~mm})\end{array}$ & $\mathrm{t}_{1}(\mathrm{~s})$ & $\mathrm{t}_{2}(\mathrm{~s})$ & Dripping \\
\hline EP-0 & 100.0 & 0.0 & 24 & NR & $>30$ & $/$ & Yes \\
\hline EP-2.5 & 97.5 & 2.5 & 27.5 & V-1 & 34 & 0 & No \\
\hline
\end{tabular}

\section{Summary}

A new type of DOPO-POSS (7Ph- $\mathrm{T}_{7}$-DOPO) was synthesized by addition reaction between DOPO and 7Ph- $\mathrm{T}_{7}$-Vinyl. 7Ph- $\mathrm{T}_{7}$-Vinyl was obtained by a substitution reaction between 7Ph- $\mathrm{T}_{7}-(\mathrm{ONa})_{3}$ and trichlorovinylsilane. FTIR and ${ }^{1} \mathrm{HNMR}$ analyses were used to characterize the structure of the two-cage compound. TGA and DSC tests were also performed to examine the properties of $7 \mathrm{Ph}-\mathrm{T}_{7}-\mathrm{DOPO}$. Results indicated that $7 \mathrm{Ph}-\mathrm{T}_{7}-\mathrm{DOPO}$ exhibited excellent

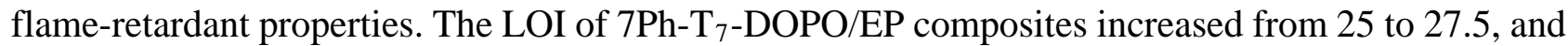
their UL-94 rating reached V-1.

\section{Reference}

[1] W. Zhang, X. Li, X.R. Yang. Pyrolysis and fire behaviour of epoxy resin composites based on a phosphorus-containing polyhedral oligomeric silsesquioxane (DOPO-POSS). Polymer Degradation and Stability. 96 (2011), 1821-1823.

[2] W. Zhang, X. Li, X. Guo, et al. Mechanical and thermal properties and flame retardancy of phosphorus-containing polyhedral oligomeric silsesquioxane (DOPO-POSS)/polycarbonate composites. Polymer Degradation and Stability. 95 (2010), 2541-2546. 
[3] W. Zhang, R. Yang. Journal of Applied Polymer Science. Synthesis of phosphorus-containing polyhedral oligomeric silsesquioxanes via hydrolytic condensation of a modified silane. Journal of Applied Polymer Science. 122 (2011), 3383-3389.

[4] Wenchao Zhang, Xiangmei Li and Rongjie Yang. Novel flame retardancy effects of DOPO-POSS on epoxy resins.Polymer Degradation and Stability. 96 (2011), 2167-2173.

[5] L. Liu, Y. Hu, L. Song, et al. Combustion and thermal properties of OctaTMA-POSS/PS composites. Journal of Materials Science. 42 (2007), 4325-4333.

[6] Li G Z, Wang L, Toghiani H, et al. Viscoelastic and mechanical properties of vinyl ester (VE)/multifunctional polyhedral oligomeric silsesquioxane (POSS) nanocomposites and multifunctional POSS-styrene copolymers.Polymer. 43 (2002). 4167-4176.

[7] Zhong H, Wei P, Jiang P, et al. Thermal degradation behaviors and flame retardancy of PC/ABS with novel silicon-containing flame retardant. Fire and Materials. 31 (2007), 411-423.

[8] Lin C H, Feng C C, Hwang T Y, et al. Preparation, thermal properties, morphology, and microstructure of phosphorus-containing epoxy/SiO 2 and polyimide/ $\mathrm{SiO}_{2}$ nanocomposites. Eur Polym Mater. 43 (2007), 725-742.

[9] M. M. Sprung and F. O. Guenther. The hydrolysis of n-amyltriethoxysilane and phenyltriethoxysilane. J. Polym. Sci. 28 (1958), 17-34.

[10]Ropartz L, Morris R E, Foster D F, et al. Increased selectivity in hydroformylation reactions using dendrimer based catalysts; a positive dendrimer effect. Chem Commun. 4 (2001), 361-362. 